EDITOR'S

CHOICE

\title{
An unusual presentation of ulcerative colitis
}

\author{
Praveen Kesav, Dheeraj Khurana
}

${ }^{1}$ Neurology, VSM Hospital, Mavelikkara, Kerala, India ${ }^{2}$ Neurology, Postgraduate Institute of Medical Education and Research, Chandigarh, India

\section{Correspondence to} Dr Praveen Kesav, drpraveenk464@gmail.com

Accepted 19 December 2014

\section{SUMMARY}

Ulcerative colitis (UC) may have diverse extraintestinal manifestations. Nutritional deficiencies, medications or immune-mediated epiphenomena are considered to be pathogenic mechanisms involved. We describe a case of a 56-year-old woman who presented with rapidly progressive tingling paraesthesias in both lower limbs followed by sensory ataxia, ascending spastic quadriparesis, urgency and urge incontinence of 3 months duration. She had an episode of bloody diarrhoea 1 month later for which a colonoscopy was carried out with colonic biopsy features revealing a diagnosis of UC. In view of lack of alternative aetiology, the posterolateral column disease in our patient was attributed to an extraintestinal manifestation of UC. She improved dramatically with a course of intravenous steroids followed by tapering dose of oral steroids and oral mesalamine for her UC. Although rare, UC should be considered in the differential diagnosis of posterolateral column disease of the spinal cord in the appropriate clinical scenario.

\section{BACKGROUND}

Although ulcerative colitis (UC) is primarily an inflammatory disease involving the colonic mucosa, it can also be considered a systemic disorder in view of its variable presentations. Extraintestinal manifestations of UC are relatively common with a lifetime risk of developing at least one of them being 50\%. ${ }^{1}$ Occasionally, UC may have prominent neurological manifestations, but UC presenting as a non-compressive posterolateral column disease is extremely rare. This case reinstates the golden dictum that extensive diagnostic evaluation is required to arrive at an aetiological diagnosis of non-compressive posterolateral column myelopathy in view of multiple differentials to be considered.

\section{CASE PRESENTATION}

A 56-year-old postmenopausal woman presented with rapidly progressive tingling paraesthesias in both lower limbs of 3 months duration. This was followed a month later by unsteadiness while walking (more at dark) and ascending weakness of hands and feet (distal>proximal) followed by autonomic symptoms in the form of urgency and urge incontinence. During the course of these symptoms she developed an episode of bloody diarrhoea lasting for a week, which subsided with a course of oral metronidazole therapy $(400 \mathrm{mg}$ three times a day for 7 days). No other systemic symptoms were observed. Physical examination revealed distal predominant weakness, spasticity, hyper-reflexia and bilateral extensor plantar response with pseudoathetosis. Posterior column dysfunction was noted in the form of abnormal joint position response (distally), impaired vibration response up to acromion process bilaterally with positive Romberg sign as well. A syndromic diagnosis of non-compressive myelopathy (posterolateral column disease) was performed and the patient was subjected to a battery of investigations in order to yield the underlying aetiology.

\section{INVESTIGATIONS}

Baseline haematological parameters including peripheral blood film were normal except for an elevated erythrocyte sedimentation rate of $51 \mathrm{~mm}$ in the first hour (normal<30). Biochemical parameters (including blood glucose, renal function, liver function, sodium, potassium, calcium, magnesium, phosphorous and lipidogram) were within normal limits. Serum ACE levels were normal. Viral markers (HIV, human T cell lymphotropic virus 1 , hepatitis $\mathrm{B}$ and hepatitis $C$ virus) were negative. Autoimmune panel revealed positive antinuclear antibody in speckled pattern $(3+)$. However, perinuclear antineutrophil cytoplasmic antibodies (p-ANCA), cytoplasmic ANCA (c-ANCA), anti-tissue transglutaminase, anti-ds DNA, anti-Ro and anti-La were negative. Serum vitamin $\mathrm{B}_{12}$ levels were $1123 \mathrm{pg} / \mathrm{mL}$ (normal $320-1600 \mathrm{pg} / \mathrm{mL}$ ). Serum and urine protein electrophoresis failed to reveal any abnormal monoclonal (M) band. Cerebrospinal fluid (CSF) analysis was acellular with elevated protein $(155 \mathrm{mg} / \mathrm{dL}$, normal 20-40 mg/dL) and normal sugar levels. CSF analysis for malignant cells and tuberculosis (TB-PCR) were negative. CSF oligoclonal band was positive on paired serum CSF sample analysis. Serum and CSF venereal disease research laboratory tests were both non-reactive. Gad-enhanced MRI of cervicodorsal spine with screening of brain was normal (figure 1). Whole body 18 flurodeoxyglucose positron emission tomography scan failed to reveal any abnormal findings. Electrophysiological studies (nerve conduction study, visual evoked potential and brainstem auditory evoked responses) were normal. Lip biopsy carried out to look for pathological features of Sjogren's syndrome was also negative. In view of an episode of lower gastrointestinal bleeding the patient was subjected to colonoscopy and subsequent biopsy. Colonic biopsy findings were consistent with UC.

\section{DIFFERENTIAL DIAGNOSIS}

All the routine differential diagnoses for posterolateral column non-compressive myelopathy were considered in the index case, such as nutritional deficiency (vitamin $\mathrm{B}_{12}$, copper), infective (HIV, human T-cell leukemia virus type 1 (HTLV-1)), auto immune (Sjogren's syndrome, systemic lupus erythematosus,) and non-infective inflammatory 
Figure 1 Normal brain MRI T2-weighted images (A) and gadolinium enhanced T1 images (B) T1 sagittal (C), T2 sagittal (D) and T2 fluidattenuated inversion recovery $(\mathrm{E})$ images of MRI of the cervicodorsal spine showing no significant cord pathology; (E) solid arrow pointing towards probable haemangioma in dorsal vertebrae D8.

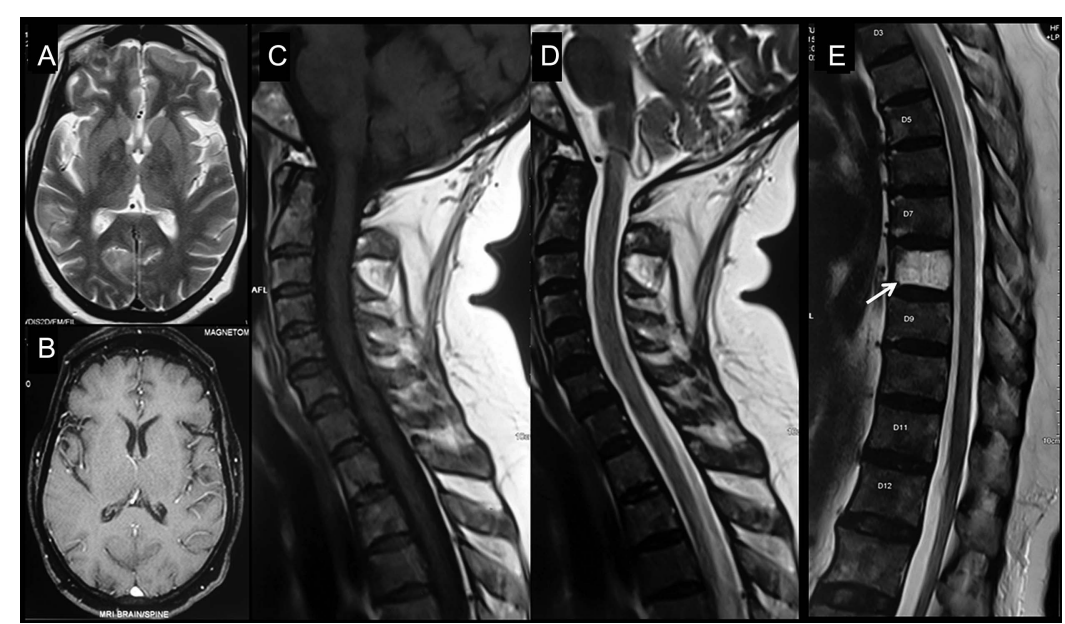

(sarcoidosis). However, all the relevant investigations were negative except for positive antinuclear antibody and positive CSF oligoclonal bands indicating an immune-mediated pathology.

\section{TREATMENT}

In view of evidence of a concomitant inflammatory disease (UC), temporal correlation between the myelopathy symptoms and inflammatory bowel disease with lack of definitive evidence for alternative aetiology on diagnostic workup, the noncompressive myelopathy in our patient was attributed to an extraintestinal manifestation of UC. As infective causes were ruled out, she was started on a course of intravenous methyl prednisolone $(1000 \mathrm{mg} /$ day for 5 days) followed by oral prednisolone $(60 \mathrm{mg} /$ day $)$ for 6 weeks. In addition, she was initiated on oral mesalamine ( $2.4 \mathrm{~g}$ daily per orally; delayed release preparation) for inducing remission of her UC with subsequent maintenance therapy.

\section{OUTCOME AND FOLLOW-UP}

The patient noted tremendous improvement in her symptoms, with ataxia and weakness improving dramatically at 1 month follow-up. Steroids were tapered over the next 8 weeks and at present she is on alternate day maintenance dose (5 mg orally). At 2 months follow-up, bladder symptoms with loss of dexterity of hands and feet remain the only significant residual deficits. No further episodes of bloody diarrhoea were observed. The initial response of the diarrhoeal episode to antimicrobials suggests an infective aetiology to be responsible for precipitation of UC in our patient.

\section{DISCUSSION}

Extraintestinal manifestations of UC are relatively common with a lifetime risk of developing at least one of them being $50 \%{ }^{1}$ However, neurological extraintestinal manifestations (central as well as peripheral) are relatively uncommon, with the majority of them being documented as isolated case reports only. The neurological extraintestinal manifestations of UC might be attributed to primarily being due to either the disease process per se (autoimmune mediated, thromboembolism) or secondary pathology (infections secondary to immunosuppression, medication related side effects, malabsorption related vitamin deficiencies and toxic/metabolic insults). ${ }^{1-3}$ Peripheral neuropathy (sensorimotor/autonomic; demyelinating and/or axonal) is considered to be the most frequent neurological disorder in
UC. ${ }^{4}$ Sensorineural hearing loss (immune mediated vestibuloacoustic neuropathy) has also been reported. ${ }^{5}$ Patients with UC are at a higher risk of developing thromboembolic cerebrovascular events, which is hypothesised to be secondary to either a hypercoagulable state or cerebral vasculitis. ${ }^{6}$ Myelopathy presenting as slowly progressive spastic quadriparesis without sensory level constitutes an extremely uncommon extraintestinal manifestation of UC. ${ }^{12}$ The exact aetiopathogenesis of myelopathy in UC seems to be speculative with nutritional (vitamin $B_{12}$ deficiency), infective (HTLV-1) and immune mediated process being considered to be the potential putative mechanisms. ${ }^{1}$ Neuroimaging studies are mostly unremarkable. Noncompressive myelopathy as the presenting manifestation of UC has been reported only once before in the literature, ${ }^{2}$ with the neurological symptoms preceding the gastrointestinal manifestations by 4 months. Our patient was unique in that the presenting feature of UC was in the form of a posterolateral spinal column disease, which has not been reported before in the literature. On initiation of steroids, significant symptomatic improvement was observed in our patient. In view of lack of definitive guidelines for the evaluation and management of neurological extraintestinal manifestations of UC, our case understates the need for extensive evaluation in order to rule out the other more common aetiology of posterolateral spinal column disease (nutritional (vitamin $\mathrm{B}_{12}$, copper deficiency), infective (HTLV-1, HIV), autoimmune diseases (Sjogren's disease)), prior to incriminating immune mediated process related to UC as the potential aetiopathogenic factor.

\section{Learning points}

- Non compressive posterolateral column myelopathy may pose a stiff diagnostic challenge in many cases.

- Immune-mediated diseases such as ulcerative colitis may rarely manifest as a posterolateral column non-compressive myelopathy.

- Ulcerative colitis should be considered in the aetiological differentials for posterolateral spinal cord column disease in the appropriate clinical scenario.

- If promptly diagnosed, significant recovery can be achieved, as exemplified in our case. 
Contributors PK was responsible for data collection, writing of manuscript and review of the literature. DK was responsible for reviewing the manuscript.

Competing interests None.

Patient consent Obtained.

Provenance and peer review Not commissioned; externally peer reviewed.

\section{REFERENCES}

1 Scheid R, Teich N. Neurologic manifestations of ulcerative colitis. Eur J Neurol 2007;14:483-92.
2 Lossos A, River Y, Eliakim A, et al. Neurologic aspects of inflammatory bowel disease. Neurology 1995;45:416-21.

3 Loftus EV Jr. Inflammatory bowel disease extending its reach. Gastroenterology 2005;129:1117-20.

4 Gondim FA, Brannagan TH IIIrd, Sander HW, et al. Peripheral neuropathy in patients with inflammatory bowel disease. Brain 2005;128:867-79.

5 Nemoto $\mathrm{H}$, Iguchi $\mathrm{H}$, Ichikawa $\mathrm{Y}$, et al. Ulcerative colitis presenting as sensorineural hearing loss, brain stem encephalopathy and white matter lesions. Neurologist 2004;10:165-8.

6 Twig G, Zandmann-Goddard G, Szyper-Kravitz M, et al. Systemic thromboembolism in inflammatory bowel disease: mechanisms and clinical applications. Ann N Y Acad Sci 2005; 1051:166-73.

Copyright 2015 BMJ Publishing Group. All rights reserved. For permission to reuse any of this content visit http://group.bmj.com/group/rights-licensing/permissions.

BMJ Case Report Fellows may re-use this article for personal use and teaching without any further permission.

Become a Fellow of BMJ Case Reports today and you can:

- Submit as many cases as you like

- Enjoy fast sympathetic peer review and rapid publication of accepted articles

- Access all the published articles

- Re-use any of the published material for personal use and teaching without further permission

For information on Institutional Fellowships contact consortiasales@bmjgroup.com

Visit casereports.bmj.com for more articles like this and to become a Fellow 